\title{
The Comparison of Clinical and Biochemical Outcomes in Off-Pump and Conventional Coronary Artery Bypass Grafting Surgery
}

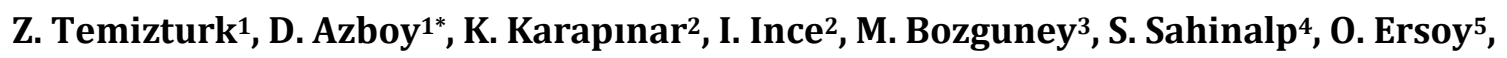 \\ A. Bulut ${ }^{2}$, E. Yucel ${ }^{5}$ \\ ${ }^{1}$ Department of Cardiovascular Surgery, Elazig Education and Training Hospital, Elazig, Turkey \\ ${ }^{2}$ Department of Cardiovascular Surgery, Ankara Yıldırım Beyazıt Education and Training Hospital, Ankara, Turkey \\ ${ }^{3}$ Department of Cardiovascular Surgery, Kayseri Education and Training Hospital, Kayseri, Turkey \\ ${ }^{4}$ Department of Cardiovascular Surgery, Van Education and Training Hospital, Van, Turkey \\ ${ }^{5}$ Department of Cardiovascular Surgery, Ankara Baskent University Medical Faculty, Ankara, Turkey \\ Email: ${ }^{*}$ ofdogan md@yahoo.com
}

Received 24 July 2015; accepted 15 August 2015; published 18 August 2015

Copyright (C) 2015 by authors and OALib.

This work is licensed under the Creative Commons Attribution International License (CC BY).

http://creativecommons.org/licenses/by/4.0/

(c) (i) Open Access

\section{Abstract}

Objective: There is no common concencus the clinical results of coronary artery bypass grafting (CABG) surgery patients who underwent off-pump or conventional techniques. Our aim of this study was to compare the changes of myocardial functions, patients' clinical results, biochemical marker release during surgery and postoperatively in On- and Off-Pump CABG surgery. Method: A consecutive series of 50 coronary artery disease (CAD) patients who underwent elective CABG surgery included for this study. The patients were divided into two groups (Group 1, N = 25 and group 2, $\mathrm{N}=$ 25). Demographic data including the patients' age, gender, body mass index (BMI), diseased coronary artery numbers, LVEF were similar. Postoperative red package blood cell, fresh frozen plasma, and thrombocyte requirements were high in 0n-Pump group $(p<0.05)$. But there was not any significant difference when compared the number of unexpected surgery because of mediastinal bleeding after operations in both groups. Preoperative and postoperative N-Terminal Pro-Brain Natriuretic Peptide (NT-proBNP), cardiac Troponin-I (cTnI) levels during and after surgery, and left ventricular ejection fractions (LVEF) prior to discharge from hospital were compared. Results: There were no statistical significancy when compared postoperative mortality and morbidity. The operations time was low in off-pump group $(p<0.05)$. The NT-proBNP levels were similar in both groups $(p>0.05)$. However, cTnI levels were significantly higher in the on-pump group $(p=0.0001)$. Postoperative LVEF decreased significantly in both groups when compared to preoperative echocardiography examinations $(p=0.001)$. But the changes of postoperative LVEFs in both groups were not statistical significant $(p>0.05)$. Conclusion: Our study results indicated that cardiac enzyme release was high after On-Pump CABG surgery. However, LVEF decreased in both techniques. There

\footnotetext{
${ }^{*}$ Corresponding author.
}

How to cite this paper: Temizturk, Z., Azboy, D., Karapınar, K., Ince, I., Bozguney, M., Sahinalp, S., Ersoy, O., Bulut, A. and Yucel, E. (2015) The Comparison of Clinical and Biochemical Outcomes in Off-Pump and Conventional Coronary Artery Bypass Grafting Surgery. Open Access Library Journal, 2: e1799. http://dx.doi.org/10.4236/oalib.1101799 
were some advantages of OPCAB operations such as decrease of inflammatory responses and angina pectoris incidence due to extracorporeal circulation; however, these techniques did not affect postoperative mortality and morbidity. Therefore, in selected cases to provide longer operation time, Off-Pump CABG could be used but it has no superiority over On-Pump CABG surgery.

\title{
Keywords
}

\section{Coronary Artery Bypass Grafting, On-Pump, Off-Pump, Left Ventricular Functions}

\author{
Subject Areas: Clinical Trials
}

\section{Introduction}

The development of the cardiopulmonary bypass pump (CPB) was a milestone in the development of cardiac surgery. However, recent studies have reported several triggered inflammatory reactions as a response to the mechano-physiological aspects of CPB. These inflammatory reactions can have both systemic and local cardiac-adverse effects [1] [2]. Nevertheless, cardiac and systemic blood supply can be safely provided with CPB when the heart is stopped [3]. Off-pump coronary artery bypass, or "beating heart" surgery, which is an alternative method for treating coronary heart disease without $\mathrm{CPB}$, has been developed in recent decades to avoid the adverse effects of CPB [3]. The literature includes many studies about the superiority claims associated with onpump and off-pump techniques [3]-[5]. However, many factors, such as experience of surgeon, can affect surgical outcomes. For this reason, reported results can be conflicting. Although some superiority can be attributed to the off-pump technique, hospital stays, the rate of total mortality, and long-term effects on organ systems such as neurological and cardiac functions, seems to be similar in the patients treated with both of these techniques [5]. Previous published studies have pointed out that the main important factor is patient selection and individualization for achieving better outcomes [6].

Myocardial enzymes release and postoperative LVEF were investigated in a number studies in On- or OffPump CABG techniques [7] [8]. But there is no any concensus about which patients definitely required offpump surgery. Thus, in our study, we aimed to compare the changes of postoperative LVEF changes in the early postoperative period in on-pump and off-pump CABG groups for investigating the changes of left ventricular functions, cardiac troponin-I release, and proBNP levels as a myocardial biomarkers.

\section{Patients and Methods}

This study was conducted between January and December 2014 in Diskapı Yıldırım Beyazıt Training and Research Hospital, in Ankara, Turkey. The study was approved by the Local Ethical Committee for Medical Research of our hospital. All study protocols were designed according to the guidelines of the Helsinki Declaration. Informed consent was obtained from all patients.

\subsection{Patient Selection and Preparation}

A consecutive series of 50 patients who had undergone elective CABG surgery were included in this prospective research. Patients with poor left ventricle (LVEF < 35\%), renal failure and concomitant heart valve disease which required repair or replacement, chronic liver disease and Re-Do operation were excluded from the study.

The patients were randomly divided into two groups.25 patients operated under CPB (Off-Pump Group 1 (OPCAB), $\mathrm{N}=25$ ). The mean number of grafted coronary artery was $3.1 \pm 0.9$ and $3.4 \pm 1.1$ in Group 1 and 2, respectively. When we compared patients data there were no any statistical significance. The mean age of the patients was $58 \pm 11.4$ y and $62 \pm 9.6$ y in group 1 and 2, respectively. 17 patients in group 1 and 15 patients in group 2 were male. In addition, there were no statistical significance when compared to number of anastomosis, except operation time. In all patients, left internal thoracic artery was used to vascularised left anterior descending artery. For other diseased coronary arteries saphenous veins were used. Sequential bypass grafting technique was used in 8 patients from group 1 and in 7 patients in group 2. All patients have multyvessel coronary artery 
or left main coronary disease. In On-Pump and Off-Pump group, coronary artery stenting was performed in seven and nine patients, respectively. In 5 patients from On-Pump and 6 patients from OPCAB have left main coronary artery disease.

BMI and systemic disease such as hypertension, and diabetes were noted in both groups. There was no any statistical significance ( $p=0.67)$. We compared total operation time, intraaorticballon pump (IABP) use, inotropic support requirement, intubation and ICU staying time in both groups by blinded ICU personels.

\section{Surgical Techniques in On-Pump Groups}

Median sternotomy was performed. Aortic and single venous cannulation was performed. CPB was instituted after the cannulation. The myocardial protection was performed has been provided using antegrade and retrograde cold blood cardioplegia after aortic cross-clamping. For LAD artery the left internal thoracic artery (ITA) has been harvested. For the remaining diseased vessels, saphenous vein was used. After distal anastomosis, cross-clamp was released and the heart is beating. If needed inotropic agent was administered prior to weaning from extracorporeal circulation. Proxymal venous anastomoses has been done using a side clamp. The crossclamp time and CPB time have been noted by the anaesthesiologist.

\subsection{Off-Pump Surgey}

After midline sternotomy, the left ITA and saphenous vein have been prepared for revascularisation. The heart is elevated using a spunch. After coronary arteriotomy, intracoronary shunt was inserted to provide blood supply and myocardial ischemia during the anastomosis. The octopus was used in all operations. Firstly, the left ITA was anastomosed to the LAD artery. After then, venous grafts have been anastomosed to diseased coronary arteries. If needed, inotropic agent was administered. After the completion of anastomosis proximal venous anastomosis were performed using an aortic side clamp.

\subsubsection{Blood Sample Collection}

To measure cardiac trophonin and Pro-BNP blood levels samples were given from venous line (Before the induction of anaesthesia, at $2 \mathrm{~h}, 4 \mathrm{~h}, 8 \mathrm{~h}$ and $24 \mathrm{~h}$. In OPCAB group, the samples collection has been given immediately after distal anastomosis. In On-Pump group, the first cardiac enzyme level has been given immediately after aortic cross-clamping. After then, the samples have been obtained at the second h, at $4 \mathrm{~h}, 8$ hy and at the and of 24. Plasma NT-proBNP has been calculated according to cTnI levels measurements.

\subsubsection{Measurement of c-TnI}

Each sample was placed into a gel containing biochemistry tubes for serum separation and centrifuged at $4{ }^{\circ} \mathrm{C}$ for 10 minutes at $3500 \mathrm{rpm}$. After centrifuge, the obtained serums were placed into small Eppendorf Tubes ${ }^{\circledR}$. Serum c-TnI levels were measured using direct automated Chemiluminescence System (ACS-180, Chicron Diagnostics, East Walpole, MA, USA) as $\mathrm{ng} / \mathrm{ml}$.

\subsubsection{Measurement of Cardiac NT-proBNP}

After blood sampling, each sample was placed into EDTA-containing tubes and centrifuged at $4^{\circ} \mathrm{C}$ for 10 minutes at $3.500 \mathrm{rpm}$. After centrifuge, obtained serums were placed into small Eppendorf Tubes ${ }^{\circledR}$. All samples were stored -80 until evaluation of the steps began for NT-proBNP. Serum NT-proBNP concentration was measured using a sandwich enzyme immunoassay NT-proBNP ELISA kit (Roche Diagnostic, Meylan, France; range $5-35,000 \mathrm{pg} \cdot \mathrm{ml}^{-1}$ ) as $\mathrm{pg} / \mathrm{ml}$.

\subsubsection{Statistical Analysis}

Data were analysed using SPSS software, version 17.0 (SPSS, Chicago, IL). Continuous variables were expressed as mean + standard deviation. The distribution of continuous variables was evaluated using the Kolmogorov-Smirnov test. Independent groups with normal distribution were compared with independent sample t-tests. The Mann-Whitney $U$ test was used to determine the difference of variables in groups with non-normal distributions. Nominal data were compared with chi-square tests. The meanings of increments in the repeated measurements were evaluated with "General Linear Model-Repeated Measures", and $p<0.05$ was considered statistically significant. 


\section{Results}

There was no mortality after surgery in both groups. The mean BMI was $26.70 \pm 3.39 \mathrm{~kg} / \mathrm{m}^{2}$ and $27.88 \pm 5.04$ $\mathrm{kg} / \mathrm{m}^{2}$ in OPCAB and on-pump groups, respectively ( $\left.p<0.05\right)$. Likewise, hypertension in 9 (36\%) vs 6 (24\%) patients in on-pump and off-pump group, respectively. Preoperative LVEF was $56.24 \% \pm 12.1 \%$ and $58.24 \% \pm$ $14.6 \%$ in group 1 and 2, respectively. These were similar in both groups $(p<0.05)$. Preoperative serum NTproBNP concentrations were $400.05 \pm 295.68 \mathrm{pg} \cdot \mathrm{ml}^{-1}$ and $388.93 \pm 459.88 \mathrm{pg} \cdot \mathrm{ml}^{-1}$ in the on-pump and offpump groups, respectively $(p<0.05)$. This was statistically significant. Preoperative and postoperative c-TnI values were $0.15 \pm 0.27 \mathrm{ng} / \mathrm{ml}$ and $0.69 \pm 011 \mathrm{ng} / \mathrm{ml}$ in on-pump group $(p=0.023)$. These values were $0.08 \pm$ $0.17 \mathrm{ng} / \mathrm{ml}$ and $0.31 \pm 0.9 \mathrm{ng} / \mathrm{ml}$ in OPCAB group. This was no statistically significant $(p>0.05)$.

Intubation time was detected as $340.16 \pm 51.73 \mathrm{~h}$ in OPCAB group. This was similar when compared to onpump group $(300.60 \pm 64.68 \mathrm{~h})(p=0.021 ; \mathrm{t}=2.388)$. The mean cardiopulmonary bypass time was $120.16 \pm 30$ $\mathrm{h}$, and the mean cross-clamp time was $69.36 \pm 20.64 \mathrm{~h}$ in on-pump group. The mean hospital staying time was $8.68 \pm 4.10 \mathrm{~d}$ and $7.36 \pm 3.89 \mathrm{~d}$ in off-pump and on-pump CABG group, respectively. In on-pump CABG the short hospital staying time was detected $(p=0.039, \mathrm{Z}=-2.060)$. One patient required inotropic support in the offpump group, while 13 (52\%) patients needed inotropic support in the on-pump group $\left(p<0.001, \chi^{2}=14.286\right)$.

The mean preoperative LVEFs were $59 \% \pm 14.5 \%$ and $61 \% \pm 7.6 \%$ in OPCAB and on-pump group, respectively $(p=0.86)$. The mean postoperative LVEF was calculated as $46.2 \% \pm 7.4 \%$ in OPCAB $(p=0.024)$. This value was calculated as $53.4 \% \pm 10.6 \%$ in on-pump group $(p=0.021)$. Intragroup analyses showed that both CABG techniques reduced LVEF after operation. Intergroup analyses demonstrated that the change of LVEF was similar.

Inon-pump and OPCAB group, preoperative mean NT-proBNP concentrations were326.50 $\pm 250.20 \mathrm{pg} / \mathrm{ml}$ and $347.94 \pm 284.20 \mathrm{pg} / \mathrm{ml}$, respectively. In On-Pump patients, these values were $390.32 \pm 371.81 \mathrm{pg} \cdot \mathrm{ml}^{-1}$, and $607.17 \pm 485.13 \mathrm{pg} \cdot \mathrm{ml}^{-1}$ at $2 \mathrm{~h}, 4 \mathrm{~h}, 8 \mathrm{~h}$ and $24 \mathrm{~h}$, respectively. In OPCAB group, serum NT-proBNP concentrations were $327.26 \pm 383.72 \mathrm{pg} / \mathrm{ml}, 335.36 \pm 362.61 \mathrm{pg} \mathrm{ml}^{-1}, 456.97 \pm 502.60 \mathrm{pg} \cdot \mathrm{ml}^{-1}, 541.92 \pm 459.25 \mathrm{pg} \cdot \mathrm{ml}^{-1}$ at 2, 4, 8 and 24 hours, respectively. Comparisons of Serum NT-proBNP concentrations of all sampling times were statistically insignificant between groups $(p<0.05)$. The distribution curves of NT-proBNP levels in the two groups are presented in Graph 1.

Cardiac Tn-I values was calculated as $4.59 \pm 4.25$ and $0.43 \pm 0.29 \mathrm{ng} / \mathrm{ml}$ in on-Pump and OPCAB group ( $p<$ $0.001, \mathrm{Z}=-5.734)$. c-Tn release was calculated at 4 . h $5.78 \pm 5.61 \mathrm{vs} .0 .49 \pm 0.27 \mathrm{ng} / \mathrm{ml}$ in on-pump and OPCAB group $(p<0.001, \mathrm{Z}=-5.890)$. At $8 \mathrm{~h}$, this value was measured as $6.58 \pm 7.97$ in on-pump and $0.65 \pm$ $0.34 \mathrm{ng} / \mathrm{ml}$ in OPCAB $(p<0.001, \mathrm{Z}=-5.908)$. At the end of $24 \mathrm{~h}$, troponin-I levels were measured as $5.39 \pm$ 7.72 in on-pump, and $0.69 \pm 0.75 \mathrm{ng} / \mathrm{ml}$ in OPCAB $(p<0.001, \mathrm{Z}=-4.680)$. These measurements were significantly different when compared to both groups. The curves of cardiac troponin-I levels in both groups are summarized in Graph 2. A comparison of preoperative and postoperative (2, 4, 8, and 24 h) NT-proBNP concentrations and cTnI values in two groups are summarized in Table 1.

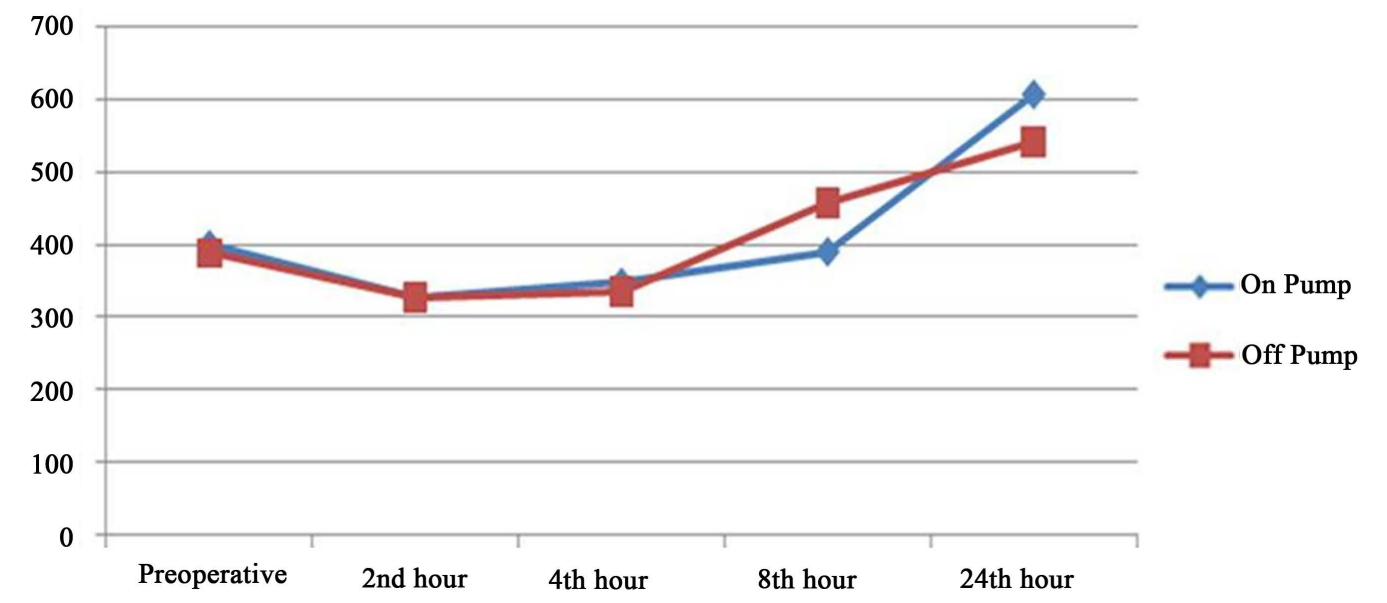

Graph 1. The distribution of NT-proBNP levels in groups. 


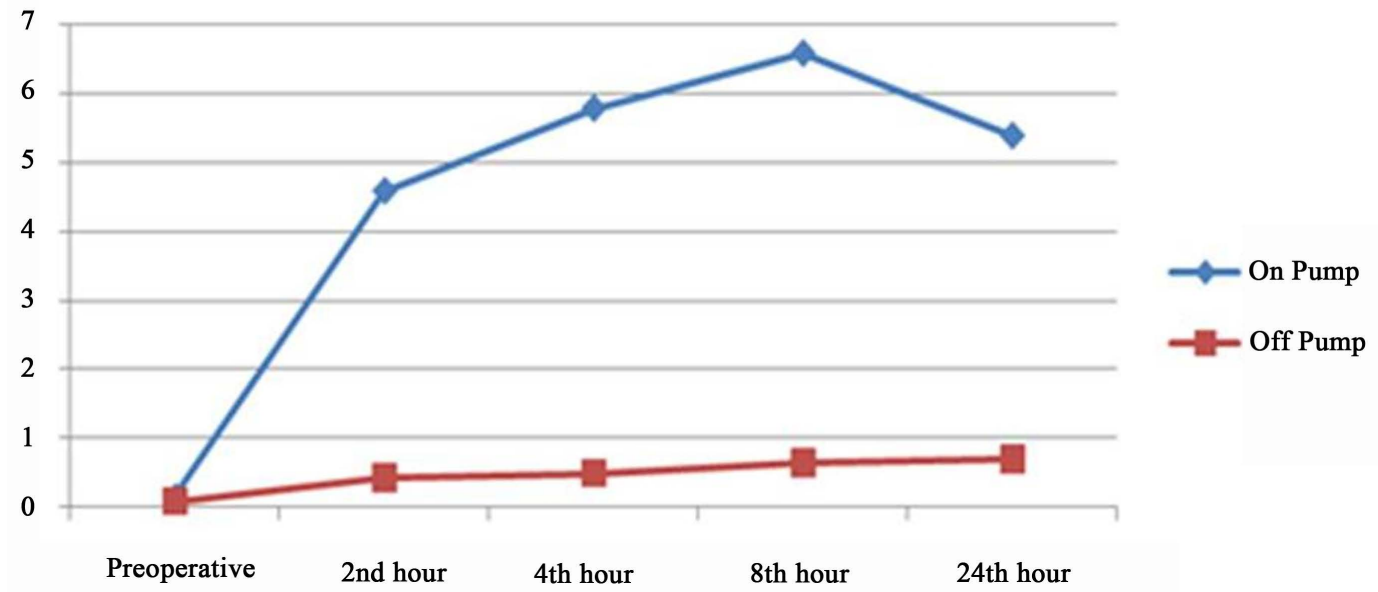

Graph 2. The distribution of cTnI levels in groups.

Table 1. NT-proBNP concentrations and cTnI values in on-pump and off-pump groups.

\begin{tabular}{|c|c|c|c|c|c|c|c|c|}
\hline & \multirow[t]{2}{*}{$\begin{array}{c}\text { On-pump } \\
\text { NT-proBNP pg } \cdot \mathrm{ml}^{-1}\end{array}$} & \multirow[t]{2}{*}{$\begin{array}{c}\text { Off-pump } \\
\text { NT-proBNP pg } \text { ml }^{-1}\end{array}$} & \multicolumn{2}{|c|}{$\begin{array}{c}\text { Mann-Whitney } \\
\text { U Test }\end{array}$} & \multirow[t]{2}{*}{$\begin{array}{l}\text { On-pump } \\
\text { cTnI ng/ml }\end{array}$} & \multirow[t]{2}{*}{$\begin{array}{l}\text { Off-pump } \\
\text { cTnI ng/ml }\end{array}$} & \multicolumn{2}{|c|}{$\begin{array}{c}\text { Mann-Whitney } \\
\text { U Test }\end{array}$} \\
\hline & & & ${ }^{*} p$ & $\mathbf{Z}$ & & & ${ }^{*} p$ & $\mathbf{Z}$ \\
\hline Preoperative & $400.05 \pm 295.68$ & $388.93 \pm 459.88$ & 0.290 & -1.057 & $0.15 \pm 0.27$ & 0.290 & 0.174 & -1.358 \\
\hline $2^{\text {nd }}$ hour & $326.50 \pm 250.20$ & $327.26 \pm 383.72$ & 0.273 & -1.096 & $4.59 \pm 4.25$ & 0.273 & 0.000 & -5.734 \\
\hline $4^{\text {th }}$ hour & $347.94 \pm 284.20$ & $335.36 \pm 362.61$ & 0.352 & -0.931 & $5.78 \pm 5.61$ & 0.352 & 0.000 & -5.890 \\
\hline $8^{\text {th }}$ hour & $390.32 \pm 371.81$ & $456.97 \pm 502.60$ & 0.839 & -0.204 & $6.58 \pm 7.97$ & 0.839 & 0.000 & -5.908 \\
\hline $24^{\text {th }}$ hour & $607.17 \pm 485.13$ & $541.92 \pm 459.25$ & 0.614 & -0.504 & $5.39 \pm 7.72$ & 0.614 & 0.000 & -4.680 \\
\hline
\end{tabular}

${ }^{*} p<0.05$ is significant.

\section{Discussion}

Significant differences were found in regard to post operative c-Tn-I values and inotropic support requirement between On- and Off-Pump techniques. But, in contrast to some previous researches [9] [10] there were no significant differences in terms of important parameters such as intubation and postoperative hospital staying time, post-surgery LVEF changes, serum NT-proBNP concentrations. In our opinion, postoperative c-TnI values after On-pump surgery were interpreted as a response to the inflammatory effect of the cardiopulmonary bypass pump.

At the beginning of the 1980s, Bufallo et al. [9] and then Benetti et collegues [10] have reported favourable outcomes with an off-pump bypass technique, which increased interest and confidence in this technique. Subsequent studies that presented similar positive results with the off-pump technique helped to faster the development and popularity of the technique [9] [10]. Collective results from these studies suggested that significantly reduced sternal wound infections, arrhythmia incidence, bleeding amount, duration of intubation, intensive care unit stays and discharge periods can be associated with this technique [9] [10]. Moreover, distal coronary an astomosis counts were reported in these cumulative studies [9] [10]. According to the previous studies, we detected a similar number of distal an astomosisin off-pump technique in our research. Additionally, more inotropic support requirements were detected in on-pump group. But, the duration of intubation and postoperative hospitalization periods were similar in both groups.

Off-pump CABG confered similar overall mid-term survival when compared with On-Pump. On-pump CABG was associated with a significant trend towards a long-term survival advantage; however, this was no longer present when subgroup analysis of only randomized controlled trials, and propensity-matched studies was performed. There was an increase in angina recurrence after Off-Pump technique but no difference was seen in previous studies. No significant differences were observed when compared secondary outcomes of both tech- 
niques. Previous analysis demonstrated comparable mid-term mortality and mid- to long-term morbidity between OPCAB and On-Pump. On-pump CABG might be associated with improved long-term survival. However, analysis of only randomized controlled trials and propensity-matched studies demonstrated comparable long-term mortality between OPCAB and On-Pump.

The most frequently discussed topics are quality of anastomosis and long-term graft patency rates for the offpump technique. Imamaki et al. reported equivalent anastomosis qualities between on-pump and off-pump techniques [11]. On the other hand, Filardo et al. reported that patients operated on using the on-pump procedure have lower long-term mortality rates when compared with the off-pump procedure [12]. Intra-aortic balloon pump requirements and mortality were not detected in our study for either procedure.

It was reported that serum NT-proBNP levels were associated with myocardial ischemia and improved ventricular functions after open heart surgery [13] [14]. Serum NT-proBNP levels were defined as a biomarker in patients with heart failure [15] [16]. Further studies revealed a relationship between NT-proBNP and coronary artery disease, ventricular hypertrophy, left ventricle diastolic function, lung disease, obesity and older age [15] [16]. Chello et al. reported that preoperative NT-proBNP levels, strongly related with left ventricular functions, can determine the postoperative recovery of the left ventricular functions [17]. While the reason is unclear, incremental NT-proBNP levels were reported after the early periods of CABG [18]. Preoperative NT-proBNP levels were similar in both of our groups. Moreover, incremental NT-proBNP levels were detected after the early operation periods in patients operated on with both off-pump and on-pump techniques. However, a significant difference between the two techniques was not detected in terms of early postoperative NT-proBNP levels at 2, 4, 8 and 24 hours. The distribution curves of NT-proBNP levels in the two groups are presented in Graph 1.

Cardiac Troponin I (cTnI) was defined as a marker of myocardial injury, which has reported to be superior insensitivity and specificity when compared with habitual biomarkers, such as creatine kinase and myoglobin [19]. However, it can be affected by the iatrogenic stressors of CABG and is not typically associated with permanent myocardial injury [20]. Furthermore, Salamonsen et al. suggested that a single cTnI measurement 24 hours after CABG can be beneficial for identifying adverse outcomes with high efficacy and simplicity [21]. van Geene et al. reported that higher postoperative cTnI levels are associated with an increased risk of hospital mortality after cardiac surgery [19]. Selvanayagam et al. reported lower postoperative cTnI levels and better left ventricular function after early periods of off-pump surgery, when compared with the on-pump technique [22]. However, they added that the off-pump procedure does not reduce the severity or extent of permanent myocardial injury [22]. We found significant increases in postoperative 2-, 4-, 8-, and 24-hour levels of cTnI in the onpump group when compared with the off-pump group $(p<0.05)$. However, there was no difference between groups in terms of EF decrement.

\section{Conclusion}

Our study results demonstrated that cardiac enzyme was low after Off-Pump CABG surgery. However, LVEF decreased in both techniques in the postoperative period. Benefits of OPCAB operations such as inflammatory response during surgery have been demonstrated previously. According to previous clinical researches, our results showed that off-pump technique could not affect postoperative mortality and morbidity in CABG operations. In our opinion, Off-Pump CABG can be used in selected CAD patients but it has no superiority over OnPump CABG. Higher postoperative cTnI levels were measured in patients operated on with the on-pump procedure; however, LVEF levels were similar compared to two groups. We need comprehensive studies for comparing on-pump and off-pump procedures in terms of short and long-term left ventricular functions and cardiac NT-Pro-BNP values.

\section{References}

[1] Gasz, B., Lenard, L., Racz, B., Benko, L., Borsiczky, B., Cserepes, B., Gal, J., Jancso, G., Lantos, J., Ghosh, S., Szabados, S., Papp, L., Alotti, N. and Roth, E. (2006) Effect of Cardiopulmonary Bypass on Cytokine Network and Myocardial Cytokine Production. Clinical Cardiology, 29, 311-315. http://dx.doi.org/10.1002/clc.4960290708

[2] Presta, P., Rubino, A.S., Lucisano, G., Serraino, G.F., Foti, D., Gulletta, E., Renzulli, A. and Fuiano, G. (2011) Preoperative Statins Improve Recovery of Renal Function but Not by an Anti-Inflammatory Effect: Observational Study in 69 Elderly Patients Undergoing Cardiac Surgery. International Urology and Nephrology, 43, 601-609. 
http://dx.doi.org/10.1007/s11255-011-9956-3

[3] Shekar, P.S. (2006) Cardiology Patient Page. On-Pump and Off-Pump Coronary Artery Bypass Grafting. Circulation, 113, e51-e52. http://dx.doi.org/10.1161/CIRCULATIONAHA.105.566737

[4] Elahi, M.M. and Khan, J.S. (2007) Revascularization with Off-Pump Coronary Artery Surgery: What Appears New Is Actually the Old Rediscovered. Cardiovascular Revascularization Medicine, 8, 52-59. http://dx.doi.org/10.1016/j.carrev.2006.09.003

[5] Sellke, F.W., Di Maio, J.M., Caplan, L.R., Ferguson, T.B., Gardner, T.J., Hiratzka, L.F., Isselbacher, E.M., Lytle, B.W., Mack, M.J., Murkin, J.M. and Robbins, R.C., American Heart Association (2005) Comparing On-Pump and Off-Pump Coronary Artery Bypass Grafting: Numerous Studies but Few Conclusions: A Scientific Statement from the American Heart Association Council on Cardiovascular Surgery and Anesthesia in Collaboration with the Interdisciplinary Working Group on Quality of Care and Outcomes Research. Circulation, 111, 2858-2864. http://dx.doi.org/10.1161/CIRCULATIONAHA.105.165030

[6] Raja, S.G., Shah, J., Navaratnarajah, M., Amin, F. and Amrani, M. (2013) Outcomes and Predictors of Mortality and Stroke after On-Pump and Off-Pump Coronary Artery Bypass Surgery in Octogenarians. Innovations (Phila), 8, 269275. http://dx.doi.org/10.1097/IMI.0000000000000000

[7] Khan, N.E., De Souza, A., Mister, R., Flather, M., Clague, J., Davies, S., Collins, P., Wang, D., Sigwart, U. and Pepper, J. (2004) A Randomized Comparison of Off-Pump and On-Pump Multivessel Coronary-Artery Bypass Surgery. New England Journal of Medicine, 350, 21-28. http://dx.doi.org/10.1056/NEJMoa031282

[8] Mangano, D. (1985) Biventricular Function after Myocardial Revascularization in Humans: Deterioration and Recovery Patterns during the First 24 Hours. Anesthesiology, 62, 571-577. http://dx.doi.org/10.1097/00000542-198505000-00005

[9] Buffolo, E. and Gerola, L.R. (2001) The Evolution of Coronary Artery Grafting on the Beating Heart. In: Salerno, T.A., Ricci, M., Karamanoukian, H.L., D’Ancona, G. and Bergsland, J., Eds., Beating Heart Coronary Artery Surgery, Futura Publishing Company, New York, 3-8.

[10] Ascione, R., Caputo, M. and Angelini, G.D. (2003) Off-Pump Coronary Artery Bypass Grafting: Not a Flash Pan. Annals of Thoracic Surgery, 75, 306-313. http://dx.doi.org/10.1016/S0003-4975(02)04020-1

[11] Imamaki, M., Masuda, M., Ishida, A., Shimura, H., Nishimura, K., Yazima, N., Ishida, K. and Miyazaki, M. (2003) Is the Quality of Off-Pump Coronary Artery Bypass Grafting Equivalent to That of Coventional Method? Kyobu Geka, 56, 699-702.

[12] Filarodi, G., Grayburn, P.A., Hamilton, C. and Comparing, R.F. (2011) Long-Term Survival between Patients Undergoing Off-Pump and On-Pump Coronary Artery Bypass Graft Operations. The Annals of Thoracic Surgery, 92, 571578. http://dx.doi.org/10.1016/j.athoracsur.2011.03.100

[13] Shirasawa, B., Hamano, K., Kawamura, T., Gohra, H., Katoh, T., Fujimura, Y., Zempo, N. and Esato, K. (2000) Does the Serum Brain Natriuretic Peptide Level after Open Heart Surgery Reflect Myocardial Protection? Kyobu Geka, 53, 123-126.

[14] Chello, M., Mastroroberto, P., Perticone, F., Cirillo, F., Bevacqua, E., Olivito, S. and Covino, E. (2001) Plasma Levels of Atriyal and Brain Natriuretic Peptides as Indicators of Recovery of Left Ventricular Systolic Function after Coronary Artery Bypass. European Journal of Cardio-Thoracic Surgery, 20, 140-146. http://dx.doi.org/10.1016/S1010-7940(01)00754-0

[15] Maisel, A. (2001) B-Type Natriuretic Peptide Levels. Cardiovascular Toxicology, 1, 159-164. http://dx.doi.org/10.1385/CT:1:2:159

[16] Richards, A.M., Nicholls, M.G., Espiner, E.A., Lainchbury, J.G., Troughton, R.W., Elliott, J., Frampton, C., Turner, J., Crozier, I.G. and Yandle, T.G. (2003) B-Type Natriuretic Peptides and Ejection Fraction for Prognosis after Myocardial Infarction. Circulation, 107, 2786-2792. http://dx.doi.org/10.1161/01.CIR.0000070953.76250.B9

[17] Chello, M., Mastroroberto, P., Perticone, F., Cirillo, F., Bevacqua, E., Olivito, S., et al. (2001) Plasma Levels of Atrial and Brain Natriuretic Peptides as Indicators of Recovery of Left Ventriculer Systolic Function after Coranary Artery Bypass. European Journal of Cardio-Thoracic Surgery, 20, 140-146. http://dx.doi.org/10.1016/S1010-7940(01)00754-0

[18] Provenchère, S., Berroeta, C., Reynaud, C., Baron, G., Poirier, I., Desmonts, J.M., Iung, B., Dehoux, M., Philip, I. and Bénessiano, J. (2006) Plasma Brain Natriuretic Peptide and Cardiac Troponin I Concentrations after Adult Cardiac Surgery: Association with Postoperatiferative Cardiac Dysfunction and 1 Year Mortality. Critical Care Medicine, 34, 995-1000. http://dx.doi.org/10.1097/01.CCM.0000206110.94385.C4

[19] van Geene, Y., van Swieten, H.A. and Noyez, L. (2010) Cardiac Troponin I Levels after Cardiac Surgery as Predictor for In-Hospital Mortality. Interactive CardioVasc and Thoracic Surgery, 10, 413-416. http://dx.doi.org/10.1510/icvts.2009.216408 
[20] Chen-Scarabelli, C. and Scarabelli, T.M. (2004) Myocardial Injury and Cardiac Troponin I Release after Off-Pump versus On-Pump Coronary Surgery. Circulation, 110, e36. http://dx.doi.org/10.1161/01.CIR.0000139384.27259.65

[21] Salamonsen, R.F., Schneider, H.G., Bailey, M. and Taylor, A.J. (2005) Cardiac Troponin I Concentrations, but Not Electrocardiographic Results, Predict an Extended Hospital Stay after Coronary Artery Bypass Graft Surgery. Clinical Chemistry, 51, 40-46. http://dx.doi.org/10.1373/clinchem.2004.041103

[22] Selvanayagam, J.B., Petersen, S.E., Francis, J.M., Robson, M.D., Kardos, A., Neubauer, S. and Taggart, D.P. (2004) Effects of Off-Pump versus On-Pump Coronary Surgery on Reversible and Irreversible Myocardial Injury: A Randomized Trial Using Cardiovascular Magnetic Resonance Imaging and Biochemical Markers. Circulation, 109, 345-350. http://dx.doi.org/10.1161/01.CIR.0000109489.71945.BD 